\title{
Thinking on the professional development of College Counselors in the new era based on the internal level of individuals
}

\author{
Huang Haiyan \\ Sichuan TOP IT Vocational Institute, Sichuan, China, 611743
}

Keywords: counselor; specialization; individual inner

\begin{abstract}
In the process of realizing the professional development of counselors, the state and universities should attach importance to the support from the macro level, and the counselors should constantly improve and upgrade from the individual internal level. This paper considers and puts forward to strengthen the inner construction of counselors from five aspects: establishing professional goals, adhering to the spirit of craftsmen, renewing the concept of learning, being good at emotional management, and improving media literacy.
\end{abstract}

\section{Preface}

All along, the Party and the state have attached great importance to the education and training of young students, and have always stressed the importance and necessity of Ideological and political education in the process of College Students' growth and success, and they stressed that counselors are the organizational guarantee of College Students' ideological and political education. No. 16 (2004) and No. 24 (2006) of the Ministry of Education clarify the important role of counselors in education and guiding the healthy growth of College students, and put forward the basic requirements for the construction of counselors; No. 9 (2013) of the Education Party Committee and No. 2 (2014) of the Ministry of Education make a new plan for training of counselors, and point out the professional development of counselors. General Secretary Xi Jinping's important speech at the National Conference on Ideological and Political Work in Colleges and Universities in 2016 and Order No.43 of the Ministry of Education in 2017 responded to the changes in the internal and external environment of Ideological and political work in Colleges and universities in recent years and the new needs of students' growth and development, which provided politics for the professional construction of counselors in the new period. Policy basis and guarantee.

\section{Professional development of Counselors}

In the era of "Internet plus", "network is everywhere", "no one is offline" and "online all the time" has become an indispensable part of the people. In addition, the diversity of College Students' values and the increasingly prominent psychological problems have made more and more variable factors in college students' work. The complexity and difficulty of work and the complexity and urgency of Ideological and political education are highlighted. Under the new situation, the 
ideological and political work in Colleges and universities can only continue to strengthen and continue to move forward. Counselors can meet the challenges and solve problems only by realizing the internal professional development of individuals, possessing good ideological and moral character, comprehensive knowledge structure, and high working ability, and accomplishing the new tasks in the new period. Therefore, to actively adapt to the new changes in the new situation, to practice the socialist core values, to pay close attention to the changes in the ideological dynamics of contemporary college students, to constantly improve the knowledge structure and enhance professional ability, and to explore new topics of Ideological and political work are to strengthen the pertinence of College Students' ideological and political education and to improve the management of students. The attitude and actions are necessary for effectiveness.

Professionalization of counselors refers to the professional growth process in which counselors gradually reach the professional standards of counselors through continuous training, learning, practice and summary in the process of fulfilling their duties. To be more precise, it refers to the process in which the individual or group of counselors have the professional spirit, professional knowledge and professional ability to engage in counselors' work through specialized training, lifelong learning, practical innovation, etc. while fulfilling their duties of Ideological and political education, learning and life guidance, psychological health counseling and crisis response. Professional development of counselors is not only a complex system engineering, but also a continuous dynamic process, which is not only the behavior of individuals but also the behavior of groups. In recent years, many scholars and experts have explored and studied the problem of counselors' professional development, analyzed the existing difficulties and weak links, and put forward relevant opinions and suggestions, such as recognizing and attaching importance to the career of counselors, accurately positioning the role of counselors, strictly selecting and appointing counselors, perfecting the incentive policies for counselors, and finishing. Good counselor training system, the implementation of counselor Title evaluation, counselor exchange platform, can be said to be fruitful research results. In the actual implementation, many colleges and universities did raise awareness and pay more attention to the counselors from the special training, professional title promotion, salary and welfare policy support, implementation and promotion, achieved some results. However, scholars and experts have studied the professional development of counselors more from the national and school level. There are few suggestions on how to discuss and give advice on the inner level of counselors.

\section{Reflections on the professional development of Counselors}

How to better promote the professional construction of counselors steadily and do a good job of practicality, from the macro level, in addition to the national and University counselors' career recognition, policy support and financial support, from the internal level, counselors as individuals, their own efforts and efforts can not be underestimated. Objective analysis of the individual status of counselors, we have to admit that in the process of professional development, there are more or less its own shortcomings. For example, counselors' own career planning and professional development are not suitable, counselors' own comprehensive quality and professional development are not suitable, counselors' own knowledge structure and professional development are not suitable and so on. To solve these problems and change the status quo, counselors should seriously consider, actively explore, courageously practice, dare to innovate from the following five aspects, and with the help of the good platform given by the school, ultimately promote their own professional development. 


\subsection{Establish career goals}

Everything an individual does must have a plan and a goal. The goal is the motivation that drives a person forward. Only when he has a goal can he determine the direction of development and persevere in it. Baidu Encyclopedia's interpretation of "career goals" is that individuals in selected areas of occupation, at a future point in time to complete the task and achieve specific goals. Career goal is a career planning and blueprint for a person. Establishing career goals is conducive to improving individual efforts, giving full play to their subjective initiative, better completing work tasks and enhancing self-ability. Similarly, counselors in this work must understand the job, enhance the sense of responsibility, determine their own career goals, not to mention the "help students to do a good career planning" and "guide students to a good career" these two tasks are still very important in counselors' work. It can be imagined that if a counselor has not established his or her own career goals, how can he or she help and guide his or her students, not to mention the professional level and actual effect of his or her guidance?

Therefore, if counselors want to know themselves correctly and evaluate themselves objectively, since they have chosen this profession, they should recognize this profession and accept the fact that they play the role of "educator, administrator and server" in their work; they should clearly understand that ideological and political education is the core of counselors' work, and they should be professional in counselors' work. Taking specialization and specialization as the ultimate goal of development, and making scientific and reasonable plans around the realization of the goal, we should further formulate feasible short-term, medium-term and long-term goals in detail; rectify professional attitudes, enhance the sense of responsibility, grasp the key points, key tasks of each stage, and devote ourselves wholeheartedly to the students and workers in accordance with the formulated goals. We should take the initiative to strengthen ideological construction and enhance professional ability to fulfill the social responsibility of educating people and ultimately achieve our professional goals.

\subsection{Adhere to the craftsman spirit}

"Special object, complex content, unlimited time" is the actual situation of counselors' work, "heavy assessment pressure, low income, difficult promotion" is also an indisputable fact faced by counselors. At present, many colleges and universities have been aware of this problem, pay more attention to the construction of the counselor team, set up a series of incentive mechanisms to guarantee, to create a sustainable development space for counselors. As counselors themselves, they should not overemphasize the external environment and conditions. They should adjust their mentality, treat their work correctly and do their work well. Only in this way can they get rid of professional confusion, experience the happiness and happiness of their work, and achieve the highest level of Maslow's hierarchy of needs theory, "self-value realization". To do this well, we must adhere to the spirit of craftsmen. Traditionally, craftsman spirit mainly refers to the spiritual realm in which artisans engaged in handicraft work devote themselves wholeheartedly, meticulously and pursue excellence in their products. The craftsman spirit has been inherited to this day, and the times have endowed with a broader and newer connotation, that is, the pursuit and quality of dedication, rigorous focus, perseverance, excellence, and courage to innovate in a variety of industries, including education.

Looking carefully at the career of counselors, we can find that many trivial and complicated things in daily work need to be handled by counselors, which can be said to be "work in detail"; furthermore, ideological work is a gradual process, requiring care, patience, responsibility, attention to details, need to be careful and delicate. Behind these work contents are all the unique craftsman's spirit, such as hard-working dedication, professional attitude of responsibility and mission, 
innovative practice style, teamwork quality, continuous value pursuit. Therefore, counselors should set up the concept of "building morality and cultivating people", carry forward the craftsman spirit of rigorous dedication, dedication, excellence, attention to details, the pursuit of perfection, and dare to innovate, teach and educate people with career feelings and a high sense of responsibility, love students, conscientiously and diligently improve their professional level and work ability. And realize self worth and harvest professional happiness.

\subsection{Update learning concept}

It is not difficult to see from the "professional competence standards of counselors" that college counselors should not only have a certain Marxist theory and ideological and political education knowledge, but also have a wide range of other management disciplines closely related to student work knowledge, but also master the comprehensive skills of coordination, communication and management, which requires counselors to pass Constantly learning to make up, optimize, perfect and improve. Although many colleges and universities have carried out various kinds of training for the promotion of counselors' professional ability, which has played a certain effect; however, because the admission mechanism of counselors does not make strict requirements for their majors, each counselor has a different knowledge structure, and counselors' own ability level is not uniform, only It is far from enough to rely solely on school training to improve knowledge structure and enhance professionalism. Therefore, counselors must update their learning concepts, establish innovative learning ideas, enrich learning methods, and improve their learning ability.

First, we should enhance the initiative learning consciousness and cultivate the habit of autonomous learning and lifelong learning. We should change our learning attitude and regard learning as a necessary task rather than as an additional task and burden. We should consciously learn professional knowledge and actively participate in school-organized learning and seminars. Second, we must learn in an all-round way and learn to learn. Not only to learn from books, master the relevant theory, but also to learn from practice, each job as a learning opportunity, everywhere as a conscious person in the work to learn experience, learn new skills, master new methods. Third, we should learn innovative learning. It is necessary to think independently, explore boldly, cultivate scientific and creative thinking habits, and raise and solve new problems in education. Only by renewing their learning concepts, learning actively, comprehensively and innovative, counselors can constantly update and improve their knowledge system, effectively enhance their professional competence, and meet various new problems and challenges.

\subsection{Good at emotional management}

As we all know, "Mental health education and counseling" and "crisis response" have gradually become new difficulties in counselors' work. Counselors generally work for college students aged 17 to 18. They are in a special period of physical and mental development. They are relatively sensitive to things, and their moods change abruptly. In addition, the complicated social environment, the quality of their parents is uneven, and there are many family divorce problems, which make today's college students psychological fragility, poor resistance to stress. It is characterized by inferiority, depression, anxiety, anger, and even suicidal behavior. Facing the increasing psychological problems and possible crises of College students, college counselors should pay attention to emotional management, apply emotional management, learn emotional management and be good at emotional management.

Emotion management is the process of perceiving, controlling and regulating the emotion of individuals and groups; good emotional management can help oneself or others to resolve contradictions and discomforts, and is conducive to enhancing the management effect. Counselors 
should master the knowledge and theory of emotion and emotion management in psychology. They should not only help students to manage their emotions, but also learn to manage their own emotions. On the one hand, counselors should go deep into students, fully grasp the individual differences of each student, strengthen communication with students, timely discover the changes of students' emotions, and guide students to express themselves actively, so as to help students to guide their emotions, regulate their emotions, eliminate troubles, and rationalize the bad words and deeds that may be triggered by negative emotions. Belief and behavior can effectively control the development of bad events. On the other hand, because counselors also play the role of "handyman, nanny, firefighter" in the work, it is inevitable to produce irritability, anxiety, depression and other negative emotions, if these negative emotions brought to work, not only will reduce work efficiency, but also will have a negative impact on students. Therefore, counselors should strengthen self-emotional management, evaluate themselves objectively, and resolve their emotions in an appropriate way; when they are in a bad mood or under too much pressure, they should try to change their cognition of the incidents, adjust and control their emotions in time, constantly encourage themselves, and face their work and life with a positive and optimistic attitude.

\subsection{Enhance media literacy}

With the rapid development of network technology in the Internet era, new media such as QQ, micro-blog, WeChat, social AP, shopping APP have been deeply integrated into people's daily life. Today's college students are fascinated and rely on new media, and become "fanatical fans" of using new media. College counselors must be conscious of the impact of new media on college students' learning, life, thinking and behavior, to adapt to the requirements of the new media era, improve their own media literacy, correctly guide students to create a healthy self-Media environment, as a good student guide role.

First of all, counselors should attach importance to and deepen their understanding of the new media, improve their information skills and information literacy, and learn to master the art of network language expression; they should change the traditional educational methods and methods, take advantage of the characteristics of the new media "no time" and "no space" restriction, and regard the new media as an interactive platform for educational work to meet the needs of multiple channels. Students need to know, at any time to answer students' questions and puzzles, so as to shorten the distance between Counselors and students. Secondly, counselors should strengthen the ability of information identification and information reconstruction, help students to distinguish the complex network information, seek advantages and avoid disadvantages, remove falsehood and preserve truth, and guide students to establish a correct value concept. Thirdly, counselors should improve their ability to deal with public opinion on the Internet, learn to collect students' opinions and suggestions through the Internet, grasp the dynamics between students and students, analyze, judge and resolve the fragmented information and extreme words that may trigger public opinion in time, and formulate reasonable disposal plans as soon as possible to guide them. Control and calm down the hazards of Internet public opinion events to a minimum.

\section{Conclusion}

The ideological and political work in Colleges and universities in the new period urgently needs the professional development of counselors. It needs the attention and support of the state and universities at the macro level. It also needs the efforts of counselors themselves from the micro level of "establishing professional goals, adhering to craftsmanship, renewing learning concepts, excelling in emotional management, improving media literacy" in five aspects. High. 


\section{Acknowledgement}

Foundation project: Humanities and Social Sciences project of Sichuan provincial education department in 2018.Research on professional identity and professional development of private college counselors. 18SB0518

\section{References}

[1] Wang Guangting, Zhou Yafu. Some Thoughts on the Professionalization of College Counselors [J. Higher Education of Jiangsu, 2010.

[2] Ying Huiping, Zhong Ye. Research on the Strategies for Promoting the Professional Ability of Counselors Based on Craftsman Spirit [J]. Newborn Baby, 2017 (33).

[3] Song Xinna. Taking the Professional Way to Be a Learning Counselor [J]. Folk Art and Literature, 2013.

[4] Li Liuxin. On emotional management of ideological and political education[J]. Age of Education, 2013 (19). 